\title{
$\begin{array}{lllllllll}T & E & S & T & I & M & O & N & Y\end{array}$
}

RAND

\section{The Pace of CalWORKs Implementation}

Jacob Alex Klerman

CT-166

February 2000

\section{Labor and Population Program}

The RAND testimony series contains the statements of RAND staff members as prepared for delivery. 


\section{PREFACE}

In response to national welfare reform legislation--the Personal Responsibility and Work Opportunity Act (PRWORA), which was signed in August 1996 and went into effect in January 1997--California passed legislation that replaced the existing Aid to Families with Dependent Children (AFDC) and Greater Avenues to Independence (GAIN) with the California Work Responsibility to Kids (CalWORKs) program. Following an open and competitive bidding process, the California Department of Social Services (CDSS), which administers CalWORKs, awarded a contract to evaluate the CalWORKs program to RAND.

This testimony--presented at a hearing of the California state Assembly Budget Subcommittee No. 1 on Health and Human Services (Assembly member Gilbert Cedillo, Chair) meeting in Sacramento, California, on February 15, 2000--discusses some preliminary results from the evaluation on the pace of implementation of CalWORKs in California's counties and the implications of that pace of implementation for past and future spending and referrals. Although this testimony is based on a variety of sources, including research conducted at RAND, the opinions and conclusions expressed are those of the author and should not be interpreted as representing those of either RAND or those of any of the agencies or others sponsoring the research, including CDSS. The second process analysis report, to be released later this year, will present final results and additional detail.

RAND is a nonprofit institution that helps improve policy and decisionmaking through research and analysis.

For more information about the evaluation, see http://www.rand.org/CalWORKs or contact:

\begin{tabular}{ll} 
Jacob Alex Klerman & Aris St. James \\
RAND & CDSS \\
1700 Main Street & 744 P Street, MS 12-56 \\
$\begin{array}{l}\text { P.O. Box 2138 } \\
\text { Santa Monica, CA 90407-2138 }\end{array}$ & Sacramento, CA 95814 \\
$\begin{array}{ll}\text { (310) 393-0411 x6289 } \\
\text { klermandrand.org }\end{array}$ & (916) 657-1959 \\
\hline
\end{tabular}




\section{ACKNOWLEDGMENTS}

This testimony is the product of the combined efforts of the RAND

Statewide CalWORKs Evaluation team, including the Co-Principal

Investigators--Gail Zellman and V. Joseph Hotz--Project Director, Elaine

Reardon, members of the Process Analysis Team--Tammi Chun, Nicole

Humphrey--and RAND programmers--Jan Hanley, Laurie MacDonald, Rodger

Madison, and Beth Roth. Paul Steinberg helped with the text, and Sandy Petitjean did a masterful job of preparing the graphics. 


\section{OPENING REMARKS}

Good morning. My name is Jacob Klerman. I am a Senior Economist at RAND in Santa Monica, California; a Professor of Economics in RAND's Graduate School of Public Policy; and the Principal Investigator of the RAND Statewide CalWORKs Evaluation, a legislatively mandated study to provide the California legislature with a "comprehensive, independent, statewide evaluation." RAND is a nonprofit institution that helps improve policy and decisionmaking through research and analysis.

My testimony today is based on a variety of sources, including research conducted at RAND as part of the statewide CalWORKs Evaluation. An earlier and more detailed version of the findings presented in this testimony was presented at the Evaluation's Advisory Committee meeting in October 1999, and a final version of this material is, by contract, to be released to the legislature later this spring. That said, the opinions and conclusions expressed here are mine and should not be interpreted as representing the opinions of RAND or the opinions of any of the agencies or others sponsoring the research, including the California Department of Social Services.

I conclude these opening remarks with a brief methodological comment. My testimony this morning is based primarily on our field work in 24 counties throughout the state over the period April to August of 1999. This field work consisted primarily of semistructured interviews with senior leadership and line workers in county welfare departments. For the most part, the testimony does not rely on hard numbers. As I will discuss, few county welfare departments could give us management reports that provide much insight into speed of implementation issues. We are addressing this data problem as part of our broader evaluation effort. In parallel with our field work, we are analyzing county data systems themselves. Preliminary results of that analysis should be available in the Summer of 2000, with results to be published in October 2000. At that time, we should have a more quantitative characterization of the status of implementation in our six focus counties: Alameda, Butte, Fresno, Los Angeles, Sacramento, and San Diego. 
OVERVIEW

Let me begin by providing an overview of our basic story. I will then return to the story and provide some detail for each of the points. Concerns have been raised about the slow pace of implementation of CalWORKs and, specifically, about large carry-overs of funds and low referrals to education, training, and treatment for substance abuse, mental health, and domestic abuse problems.

Our analysis allows us to explain why implementation has been slow, spending has been below budget, and referrals have been low. Figure 1 sums up the key points of our analysis on this subject.

\section{Why Has Implementation Been Slow?}

- Workload increased

- Requiring CWDs to add capacity

- Cases need to move through the early steps of the CalWORKs process

- In a "work first" program, only then will referrals occur

Monitorable: Time to first WTW activity, sanction, or work Ameliorable: Add "enough" capacity $\stackrel{\text { RAND Sta tewide }}{\equiv}$ CalWORK

Figure 1--Why Has Implementation Been Slow

As I will discuss, CalWORKs massively increased the workload of the county welfare departments, requiring them to add capacity--either inhouse staff, outside contractors, or both. Bringing that additional capacity on-line took time. Only once the additional capacity was online could the work of actually moving the existing and new cases through the early steps of the CalWORKs model proceed. In many 
counties, that capacity did not come on-line until the spring of 1999 or even later. Some counties are still trying to add capacity now, early in 2000 .

This time required to add capacity has several implications.

- Recipients would not move through the steps of the CalWORKs welfare-to-work model until there was enough capacity to hold meetings with caseworkers and enough seats in Job Club.

- After the resolution of some ambiguity in the CalWORKs legislation and the early regulations, current policy is that the CalWORKs legislation's 18/24-month clocks do not start to tick until after a welfare-to-work plan is signed, which would be after Appraisal, Job Club, and Assessment. Thus, large scale mandatory community service is still half a year or more away •

- CalWORKs is a work-first program, and thus large numbers of referrals would not be expected until after Assessment.

- Expenditures would not rise until new employees were being paid, welfare-to-work plans should be being signed, and contractors were billing, and caseworkers were referring recipients to Job club and other services.

And, none of this could occur until after the capacity came on-line, and cases began moving through the steps of the CalWORKs welfare-to-work model.

While we can explain why implementation has been slow, these explanations do not change the reality: Many CalWORKs recipients are now two years into their five-year lifetime time limit and have still not received many of the services that the CalWORKs legislation provides. Similarly, it appears that, in some counties, new cases are not being moved promptly through the sequence of activities specified in the CalWORKs legislation. Finally, I will argue that this situation can be monitored (we suggest outcomes to monitor) and that the situation can be ameliorated (by adding enough capacity). 


\section{WORKLOAD}

To understand the pace of implementation of CalWORKs, it helps to take a step back and understand what the CalwoRKs legislation expected of a county welfare department. The welfare caseload has declined by about a third, so many observers assumed that the workload and, thus, the required staffing to meet that workload, could also decrease. However, the reality has been quite different: The workload has increased dramatically.

Compared to AFDC and GAIN programs that it replaced, the CalWORKs legislation had a different and more intensive vision of service delivery. Welfare-to-work services that had been previously provided to only a quarter of the caseload were to be nearly universal under CalWoRKs. As more people were required to participate, it was clear that more would not comply and that county welfare departments would need to process more sanctions. In addition, both as a result of the reforms and of the improving economy, more cases were working; this, in turn, requires more effort to record monthly earnings of those working and to recompute their grants. Finally, someone had to arrange for the new services to be provided under the legislation--child care, education, training, and treatment for mental health, substance abuse, and domestic abuse problems. Clearly, more "capacity" (staff or contractors) would be needed to handle each case.

This analysis refers to the steady-state workload. In the shortterm, there was even more work. Not only did the county welfare departments have to process new cases through this expanded set of activities, they also needed to process many of the existing cases through those same activities. In most counties, there were about three times as many existing cases as there would be new cases in any given year.

All things considered, counties could project that their short-term workload would double or triple. Clearly, additional capacity would be needed. 


\section{ADDING CAPACITY}

Adding capacity, whether in the form of new in-house employees or in the form of new outside contractors, would prove to be neither easy nor instantaneous. Any new capacity needed to be arranged and then added simultaneously with the county welfare department's efforts to design and implement new welfare programs consistent with the CalWoRKs legislation. Furthermore, in many counties, the Board of Supervisors or the Chief Administrative Officer was strongly opposed to hiring in general and for welfare programs in particular. In other counties, the Board of Supervisors and the public-sector unions were strongly opposed to outsourcing. In either case, the nature of government hiring and contracting implied that new capacity could not be brought on-line instantaneously. Further complicating the management problem, once the existing caseload moved through the system, the workload would be expected to decrease. Thus, county welfare departments needed to expand capacity in a way that could be contracted once the existing caseload was processed. Finally, in many counties, there were further delays for reorganization of the workforce, reclassification studies, union issues, lawsuits, and shortages of space in which to put new employees and contractors.

We can divide the counties into three groups in terms of how they dealt with the need to add capacity:

- Some counties had large GAIN programs or successful, flexible contracts in place. They ramped up quickly, putting sufficient capacity in place by late 1998 and moved the bulk of their existing caseload through Job Club in early 1999.

- Most counties were not so favorably situated. They moved promptly to add capacity, but new contracts did not yield new capacity until early in 1999. Hiring and then back-filling positions vacated as lower-level employees moved into the newly created positions took even longer. Many county welfare departments report that they had not completed hiring until the summer of 1999. In this largest group of counties, the bulk of 
the existing caseload completed Job Club in the Summer of early Fall of 1999 .

- Finally, some counties, apparently including many of the larger ones, encountered one of the serious obstacles I listed earlier, did not act promptly, or underestimated the workload. As of late 1999, they still had a large portion of their existing caseload awaiting Job Club.

\section{EXPLAINING SLOW IMPLEMENTATION}

Given this analysis, we can explain much of the experience of the last two years and provide constructive comments for the future. County welfare department expenditures will not rise until the new capacity (staff or contractors) are on-line and billing. In as much as county CalWORKs programs have a direct effect, recipients will not be more likely to get jobs until they participate in job search/Job club and as necessary the follow-on welfare-to-work activities. Child care expenditures will not rise until recipients are actually in activities or work requiring child care. Referrals to education, training, and treatment for mental health, substance abuse, and domestic abuse problems will not increase until recipients are screened for such services after failing to find work. The 18/24-month clocks toward mandatory community service will not begin to tick until welfare-to-work plans are signed. Those plans will not be signed until a recipient completes Job Club without finding a job, is assessed, and then meets again with a caseworker.

For these referrals, the crucial timing issue when does a recipient start the first welfare to work activity, as shown in Figure 2. In a "pure" work-first program, services are only provided to make people employable, and the labor market is viewed as the best test of employability. Some people who we would have deemed clearly employable will not find jobs; others who we would have deemed clearly not employable will find jobs. Therefore, everyone is sent to job search. People who find a job have revealed that they do not need the services. Only those who do not find a job are referred to services. This will not occur until after they are formally assessed and have signed a 
welfare to work plan. This accounts for the solid lines from welfare to work plan to the yellow boxes in Figure 2 .

\section{The CalWORKs Model}

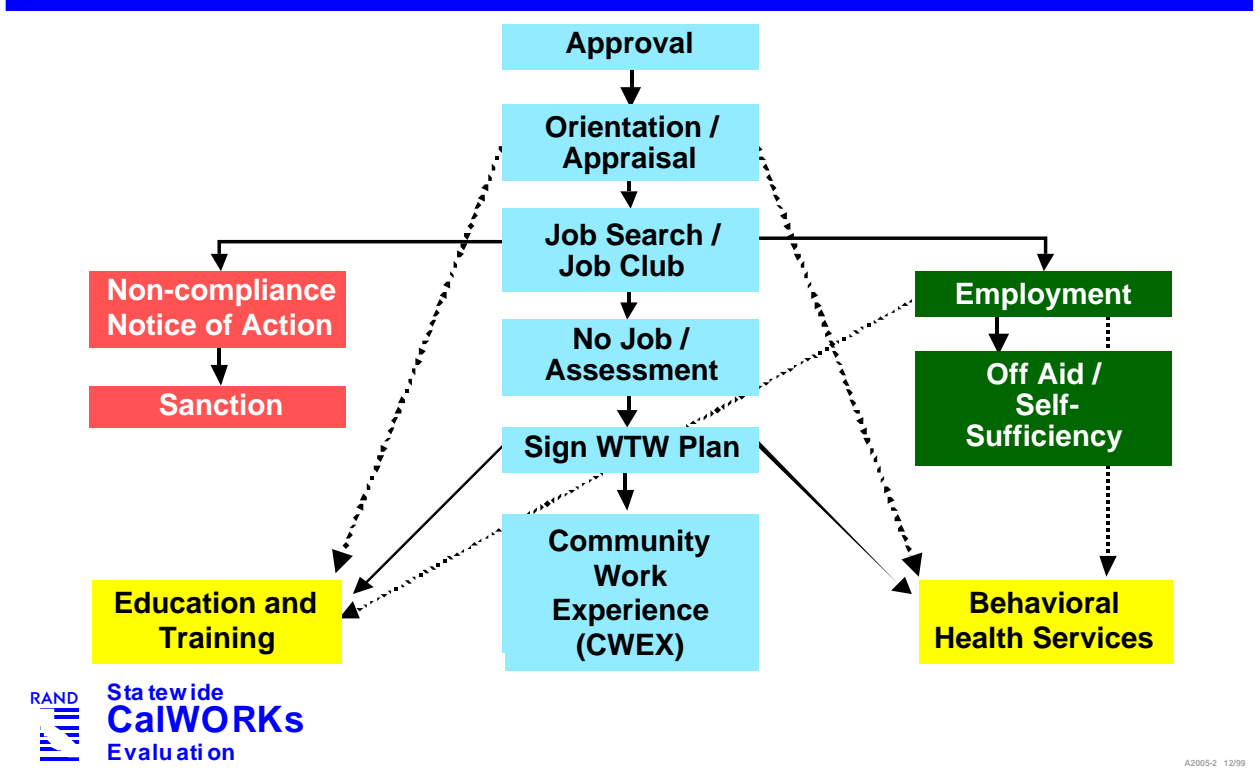

Figure 2--The CalWoRks Model

However, CalWORKs is not a "pure" work-first program. Formal and informal guidance from the state and the choices of many counties imply that some people will be referred before job search (the dotted lines from orientation/appraisal to the yellow boxes in Figure 2), while others will be referred concurrently with employment (the dotted lines from employment to the yellow boxes in Figure 2). Nonetheless, the basic insight is correct: In a work-first program such as CalWoRks, most referrals would be expected to take place as a welfare-to-work activity, following assessment and the signing of a welfare-to-work plan. For referrals to occur through this primary path, recipients actually have to reach assessment and then sign welfare to work plans.

\section{THE EFFECTS OF CAPACITY}

The crucial question then is: When do recipients reach job search and the follow-on welfare-to-work activities that are the core of the CalWoRKs program model? In an ideal program with sufficient capacity, a 
new recipient should be able to sign a plan and begin the first welfareto-work activity within ten weeks of the approval of her application, as represented by the green bars on Figure 3 ).

\section{Time to Referral}

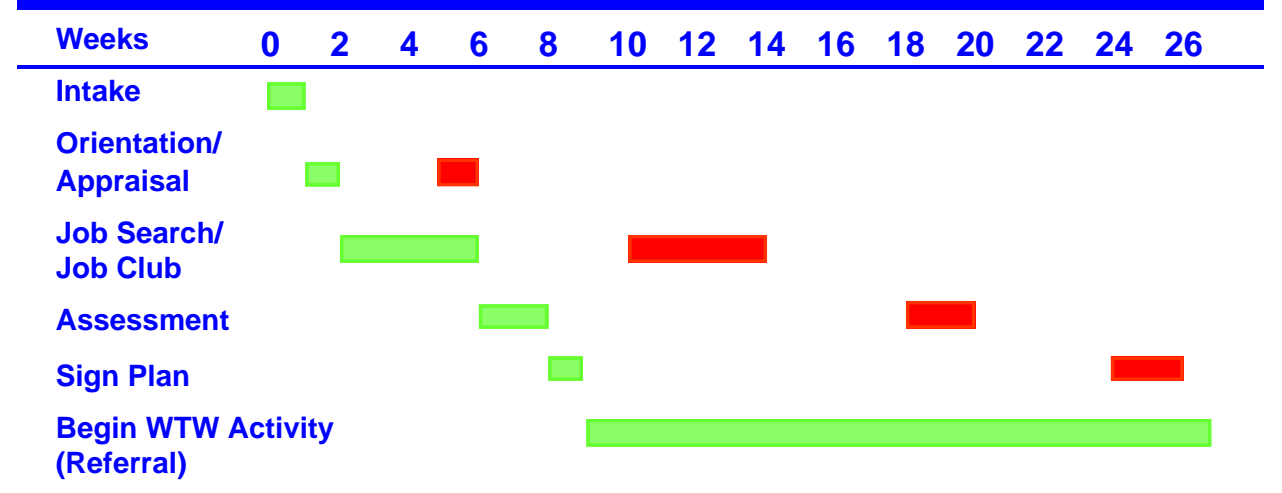

"If it takes longer, we lose the message:

Aid is connected to jobs. Time on aid is limited.

The clock is ticking."

SAN Stawide
CalWORKs
Evaluation

Figure 3--Time to Referral

Reading across the green bars in the figure, we see that intake (or approval) would take place in week 1; orientation/appraisal, in week 2; four weeks of job search/Job Club, in weeks 3-6; assessment, in weeks 78; signing a welfare-to-work plan, in week 9; and beginning the first welfare-to-work activity, in week 10 .

Although this is a schedule county welfare departments can aspire to, it is very hard schedule to achieve. Doing so would require having sufficient capacity so that each step can occur almost immediately after the previous step, even given short-term variation in the caseload.

Instead, in many counties, there is a gap of a month or more-waiting for an open appointment or a new group to begin--between each step (the red bars in Figure 3). Thus, what might take as little as ten weeks, takes six months or more. The end result is that two years after CalWORKs became effective, many of the existing cases have not yet begun 
a first welfare-to-work activity; in some cases, they have not even begun job search/Job Club.

Shortening this schedule requires two things:

- First, the county needs to have enough capacity;

- Second, the county needs to have administrative procedures and data systems in place to ensure that cases don't get "lost."

\section{MONITORING CaIWORKS OUTCOMES}

This analysis suggests an approach to monitoring CalWoRKs outcomes. We want to know how fast cases are moving past the initial phase of the CalWoRKs model-job search. There are four different ways to leave this initial phase of the CalWorks model:

1. A small number of participants are pre-screened into education or treatment for substance abuse, mental health, and domestic abuse.

2. Some participants complete job search without find a job. They enter the next phase after they are assessed, sign a welfare to work plan, and begin a welfare-to-work activity (the center column and the bottom row of Figure 2), but they are probably the smallest group.

3. A third or more of participants appear to be noncompliant; their county welfare department has instructed them to participate in some activity, but they have not done so (the left column of Figure 2, in red because this is the worst outcome). For them, the county welfare department should have begun the formal noncompliance process by sending a Notice of Action, and then following it up by imposing a sanction (cutting the benefit).

4. A third or more of participants are working or have left aid (the right column of Figure 3, in green because this is the desired outcome) .

We would like to know what percentage of cases are in each of these four groups (or paths); either in a welfare-to-work activity, or deemed 
noncompliant, or working (including leaving aid); and how these percentages change over the weeks following intake approval. It should be possible to get cases to this point in ten weeks or less. If after twelve to sixteen weeks a case is not in one of these three groups, something is wrong. The recipient's clock is ticking, but he or she is not receiving the services provided for in the CalWORKs legislation.

A similar analysis applies to the cases who have been continuously on aid since CalWORKs began in January 1998. Now, two years after implementation, every one of those cases should be in one of these four groups. Otherwise, two years of their five-year lifetime limit has been spent without receiving the basic CalWORKs services.

Unfortunately, many counties appear to be far from these goals both for new cases and for existing cases. Exactly how far and the relative success of California's 58 counties is not clear. As I noted at the outset, most county welfare departments could not provide management reports that clearly described the status of their cases.

This inability of counties to report such information is troubling beyond our desire to monitor CalWORKs implementation. A standard management adage posits: "What gets measured gets done."

\section{CONCLUSION}

In summary, CalWORKs massively increased the county welfare department's workload, requiring them to add capacity--staff, contractors, or both. Bringing that additional capacity on-line took time. Only once the additional capacity was on-line could the work of actually moving the new and existing cases through the early steps of the CalWoRKs model proceed. In many counties, that capacity did not come on-line until the spring of 1999 or later. Moreover, because CalWORKs is a work-first program, large numbers of referrals to education, training, and treatment for mental health, substance abuse, and domestic abuse problems would not be expected until cases complete these early steps of the CalWORKs model.

In counties that have enough capacity in place, the bulk of cases should have signed welfare-to-work plans in the last few months. Assuming that the county is screening heavily and making referrals 


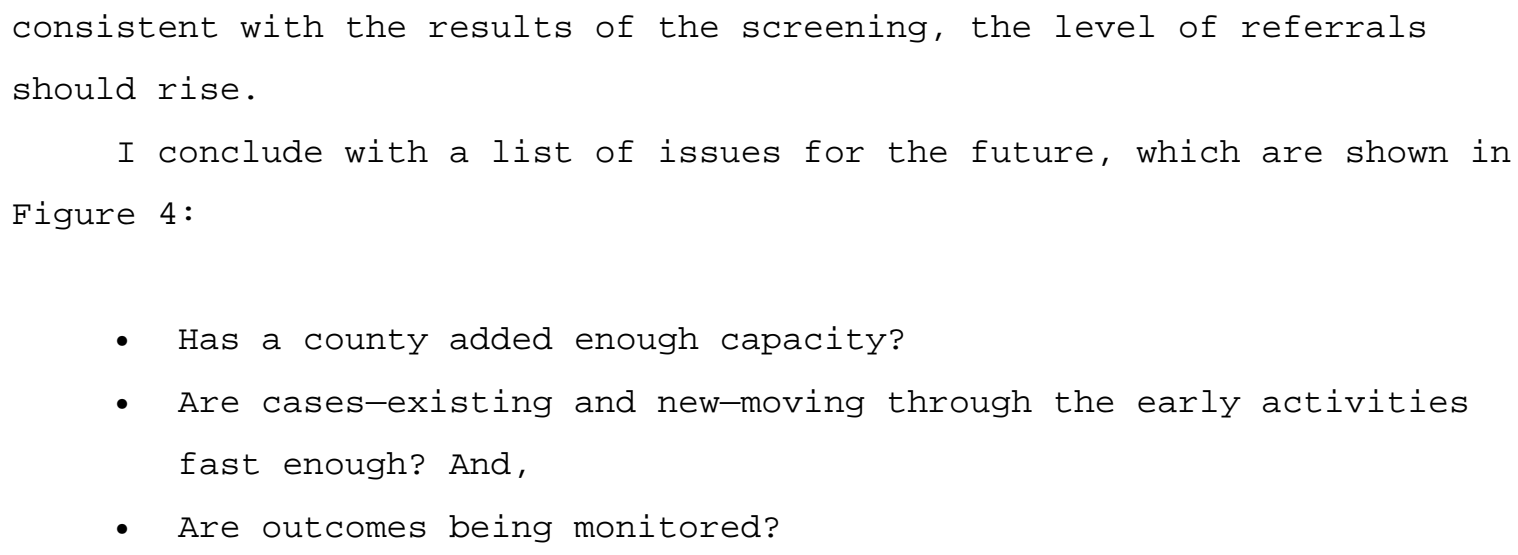

\section{Issues for the Future}

- Has a county added enough capacity?

- Are cases-existing and new-moving through early steps fast enough?

-What outcomes are being monitored?

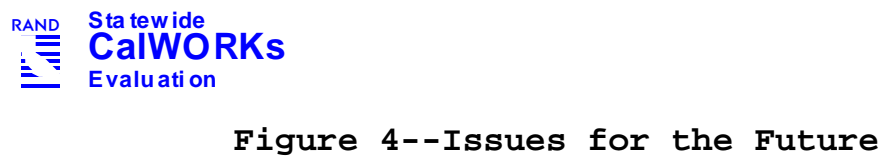

